\title{
EL PROBLEMA MORISCO EN SICILIA
}

Varias obras de historiadores antiguos o recientes han estudiado la presencia del Islam en Sicilia; sin embargo, todos hacen caso omiso de un aspecto de esta presencia: la de los llamados "moriscos", es decir de estos musulmanes convertidos en España al cristianismo y luego expulsados, como consecuencia del fracaso de la conversión. Hemos encontrado la huella de estos moriscos estudiando los procesos inquisitoriales conservados en el Archivo Histórico Nacional de Madrid'; efectivamente, la Inquisición los persiguió por seguir siendo fieles al Islam.

Es de notar que, en su lucha contra el "mahometismo", el tribunal del Santo Oficio de Sicilia ocupa el cuarto lugar, en cuanto se refiere al número de procesos (763), después del de Valencia (2744), Zaragoza (2668), y Granada (1635) ${ }^{2}$.

Sin embargo, si consideramos ahora más precisamente el período posterior a la expulsión de los moriscos, es el tribunal de Sicilia el que lleva la palma con un total de 261 causas, lo que quiere decir que en Sicilia se planteó el problema con gran intensidad y siguió planteándose cuando ya casi no lo era en España.

En efecto, por su situación geográfica y su población cosmopolita, Sicilia está en relación estrecha con el mundo musulmán. Allí, pues, la Inquisición se mostrará particularmente celosa por ser la isla el punto de contacto directo entre el mundo cristiano y el mundo turco-magrebí ${ }^{3}$.

${ }^{1}$ Los legajos utilizados son los siguientes: A.H.N., sección Inquisición; leg. 1747, I y II; leg. 1748. Libro 898 (15 47-1597), lib. 899 (1597-1616), lib. 900 (1616-1628), lib. 901 (1628-1640), lib. 902 (1640-1702).

${ }^{2}$ Sacamos estos datos de la ponencia de Jaime Contreras, "Las causas de fe en la Inquisición española: 1540-1700. Análisis de una estadística" en el Simposium interdisciplinario de Inquisición medieval y moderna, Dinamarca, 59 sept. 1978 (actas en prensa). Es un trabajo esencial para un conocimiento estadístico en profundidad de la Inquisición.

${ }^{3}$ Otra fuente de informaciones, particularmente interesante, es la obra de fray Diego Haedo, Topografía e historia general de Argel, Valladolid, 1612, publicada por la Sociedad de Bibliófilos Españoles, Madrid, 1928. Don Diego 
Pero desde ahora, hay que dar una precisión: todos los procesos por islamismo no se refieren a moriscos. A tres grupos persigue el Santo Oficio: primero a los llamados "renegados"; son los más numerosos. Segundo a los "cristianos nuevos de moros o de turcos"; es el segundo grupo en importancia numérica. En fin, a los llamados "moriscos" propiamente dicho. El primer proceso referente a uno de ellos es de 1547, y el último de 1639. El número total de moriscos procesados es de 63 personas, el de cristianos nuevos, de moros o turcos, de 150 personas, y el de los renegados de 550. Notemos que, a veces, hay interferencias entre los tres grupos. A los unos como a los otros, se les nombra en ocasiones "cristianos renegados"; es el caso por ejemplo de Hernando de Vilanueva ${ }^{4}$, a pesar de ser morisco oriundo de Tabernas, en el reino de Granada. De la misma manera, se dirá de otros que son "de raza de Moros", siendo ellos nativos de Aragón. Eso nos prueba que lo que interesaba a la Inquisición era luchar contra el Islam, representado por renegados, cristianos nuevos y moriscos.

Nos interesa aquí esencialmente el tercer grupo, el de los moriscos procedentes de España, pero no se puede prescindir totalmente del segundo, ya que es para Sicilia lo que es el morisco para España: un cristiano nuevo de moro (así se llamaron en un primer tiempo los moriscos en España). Además, precisemos que, si no encontramos más moriscos después de 1639 es porque éstos han perdido ya su apelativo, y porque la generación siguiente no menciona ya su origen hispánico, por haber nacido en el Magreb o en otra región islámica.

Cristianos nuevos de moros o turcos y moriscos tienen un mismo problema: se encuentran en Sicilia en contra de su propia voluntad, y para resolverlo van a intentar por todos los medios regresar a tierra del Islam.

Un esquema tipo de esta empresa se deduce de varios procesos. Primero son los preparativos. No suele ser empresa personal sino de varios: uno roba una barca, otro una sábana que servirá

de Haedo fue obispo de Palermo, luego capitán general del reino de Sicilia, y se interesó mucho por ios cautivos en las mazmorras de Argel, Tánger y otras ciudades de la costa berberisca, ayudando a su rescate. El arzobispo y su sobrino tomaban apuntes de sus conversaciones con los recién rescatados, y el sobrino escribió a partir de estos datos la Topografía... En este libro encontramos también algunos datos sobre los moriscos; por ejemplo nos precisa que los famosos bergantines utilizados para el corso se fabricaban en Cherchell, cerca de Argel: "Los maestros dellos son todos Moriscos de Grana" da, Valencia y Aragón, de los cuales está todo aquel̆ lugar ller̃o y poblado".

${ }^{4}$ A.H.N., sección Inquisición, lib. 898, fol. 528r, 1586. 
de vela, y otros vendrán con algunas provisiones. Si se les sorprende, resisten y se defienden con espadas. La huida, por más seguridad, se emprende de noche; tienen la esperanza de llegar a las costas de Túnez a la noche siguiente, y mejor para ellos si encuentran barcos turcos o franceses que vayan hacia allá. En caso de captura, los guardias los entregan a la Inquisición, interpretándose su huida como un deseo de apostasía. Los reos, en su defensa, dirán que no podían soportar las sevicias de su amo, y que no deseaban más que ser "hombres libres". Uno se expresa así: "Que los pájaros procuraban su libertad, huyéndose de las jaulas". Además, muchos pretenden que se dirigen hacia Roma.

En esto interviene la Inquisición, que quiere conocer las motivaciones profundas de la huida; y en este caso preciso, muchas veces se votará el tormento: "Se votó fuese puesto a questión de tormento ad arbitrium sobre la intención". El resultado más frecuente es que el acusado confiesa que quería irse a Berbería "a tornarse moro".

Otro punto de contacto entre el grupo de los cristianos nuevos de moros y los moriscos es su situación social. En su gran mayoría son esclavos, con algún porcentaje de libertos. Pero se les suele casi siempre nombrar en relación con sus amos. Si los primeros fueron tomados en acciones guerreras (se nombran varias batallas, como Lepanto, Gelves...) o en corso, y luego no resistieron las presiones que se les hacía para convertirse, los segundos vinieron con sus amos desde España, donde fueron esclavizados sea por haber participado a alguna de las sublevaciones moriscas, esencialmente en la guerra de las Alpujarras o en los levantamientos coetáneos de la expulsión, sea por haber venido en corso en las costas de España. A otros se les llama "moriscos de los expulsos": son los que salieron en el momento de la expulsión general y las circunstancias varias de la vida los han traído hasta aquí. Entre ellos, algunos se establecieron en un primer tiempo en Argel o en Túnez, y luego vinieron en corso con otros musulmanes. Éstos, al ser procesados, intentarán siempre esconder su origen morisco para no incurrir en la acusación de apostasía. A algunos de ellos se les sacó, después de una denuncia, de las galeras de Sicilia, donde cumplían su pena civil, para incoar un proceso inquisitorial contra ellos "por haber vuelto a practicar los ritos de la secta de Mahoma".

¿Cuáles son las penas que reciben los moriscos, y a qué delitos corresponden? Numerosos son los condenados a galeras. Esta observación vale para los moriscos como para los cristianos nuevos, los renegados, o cualquier persona cogida en corso. En es- 
te caso, el castigo de la Inquisición no hacía más que corroborar el fallo del tribunal civil. Leemos en uno de los procesos: "En esto de las galeras, no hay que hacer mucho reparo, porque la verdad, se ponen más por formalidad de la sentencia que por castigo. Porque todos estos renegados que vienen en corso tienen galeras perpetuas por ley real y observancia deste reyno, y aunque no se les hubiera dado el tribunal, no por eso dexarán de tenerlas, pues leída la sentencia, se habían de restituir a las galeras, de donde se sacaron, y en ellas es fuerza que sean galeotes de por vida según el orden del rey".

Además, se les dan penitencias espirituales y se les viste el sambenito, que quitarán antes de subir al barco. En un primer tiempo, se les obligaba a llevarlo en las mismas galeras, pero los galeotes o lo tiraban al mar, o lo desgarraban, o los demás compañeros hacían escarnio a la cruz de San Andrés dibujada en él.

En el caso de huida hacia tierras del Islam, el reo abjuraba y se le reconciliaba. Además, para la ejemplaridad del caso, se le azotaba por las plazas y calles de Palermo, y se pregonaba el motivo del castigo. En caso de circunstancias agravantes, se le condenaba a penas de galeras de tres a siete años.

Como en la Península, se aplican las distintas penas previstas para los delitos que se solían reprochar a los moriscos, siendo el principal el haber vuelto al Islam. En este caso, se les reconciliaba, se les daba penitencia y se les imponía el hábito. En la mayoría de los casos, un sacerdote estaba encargado de su enseñanza religiosa.

Encontramos también los procesos habituales por bigamia, hechicería o blasfemia. Estos últimos son muy numerosos, y las blasfemias cobran una particular virulencia. Sin saberlo quizás, van en contra de las creencias tradicionales del Islam, que ve en Cristo un profeta y en María una persona excelsa, y se exclaman: "Mal haya Cristo cornudo, y Nuestra Señora puta barragana, que sea matada".

Los procesos son muy interesantes por los datos que nos ofrecen en cuanto a la vida de estos moriscos. El relato que hacen de su vida ajetreada es para el historiador de un interés máximo. Ellos mismos nos dan precisiones sobre su vida anterior en España, y siempre la presentan como una.vida islámica, pero oculta: uno de ellos nos cuenta que sus padres en Valencia habían convertido la parte subterránea de su casa en mezquita, donde acudían los vecinos a rezar.

La lectura de estas causas nos permite además conocer mejor sus andanzas por el mundo mediterráneo a partir del momento 
de la expulsión. Algunos casos llaman particularmente nuestra atención como el de Juan Camar, de oficio arriero, que compareció espontáneamente ante el tribunal, que le hizo contar su vida: había sido llevado con otros moriscos a Argel, donde estuvo año y medio al servicio de un turco, "haciendo vida de Moro con sus cerimonias, yendo a la mezquita por cumplir con ellos y porque no le hiziesen mal". Cuenta que allá se echó un bando para que todos los moriscos que habían venido de España se retajasen so pena de ser esclavos. Él cumplió el bando, aunque tenía intención de volver a tierra de cristianos, porque su madre, cristiana vieja - antes casada con un morisco - se había quedado en España. Se embarcó en un bajel con ocho ingleses y un flamenco, otros renegados. Pero en el trayecto, los ingleses se hicieron señores del bajel y, al llegar a Malta, vendieron a los moros como esclavos; de allí fue traído a Palermo y vendido. El tribunal tuvo con él las audiencias ordinarias, e hizo las diligencias para saber su intención. Se votó que fuese absuelto "ad cautelam", se confesase y dijese "la corona de Nuestra Señora" los domingos y fiestas durante seis meses y ayunase los viernes. Bien podemos suponer que intentó regresar a España.

Otro caso interesante es el de Catalina Barón, natural de Bellús, en el reino de Valencia. Ha sido denunciada por un primo hermano suyo, natural del mismo pueblo, morisco, y como ella, esclavo. Pero el amo de Catalina acaba de libertarla y concederle un pasaporte para ir a Túnez, "sin pagar duana ni otro derecho alguno"; para obtener tal facilidad, no confesó su origen; siempre dijo desde su llegada a Sicilia que era mora. Pero no contaba con la acusación de su propio primo ni con los testimonios de las vecinas, que contaron al tribunal las confidencias de la rea. En un primer tiempo se votó su relajación, por ser pertinaz; pero después hubo un nuevo fallo, dijo que se convertía, y obtuvo la reconciliación. El relato que hace de su vida es muy curioso: cuando la expulsión, se embarcó con su marido en el puerto de Cartagena de donde pasó a Orán. Allí, antes de emprender el camino por tierra argelina, fue raptada por el gobernador de la galera, quien, al cabo de cierto tiempo, la regaló a otro patrón, y éste la trajo a Palermo, donde la tuvo por esclava algún tiempo. Después pasó al servicio del marqués de la Mota, que la libertó, como se ha dicho.

Estos dos ejemplos que acabamos de comentar nos muestran que los moriscos son seres dotados de una doble personalidad y, según las circunstancias, los vemos inclinarse hacia un lado u otro. Uno viene a confesarse espontáneamente, otro denuncia a 
LA REPRESIÓN INQUISITORIAL CONTRA EL ISLAM EN SICILIA.

Número de procesos entre 1540-1700:

\begin{tabular}{|c|c|c|}
\hline $1540-1559$ & $1560-1614$ & $1615-1700$ \\
\hline 11 & 471 & 261 \\
\hline
\end{tabular}

Número de procesos entre 1560-1615:

\begin{tabular}{|c|c|c|c|c|c|}
\hline $1560-1564$ & $1565-1569$ & $1570-1574$ & $1575-1579$ & $1580-1584$ & $1585-1589$ \\
\hline 0 & 1 & 75 & 61 & 34 & 39 \\
\hline
\end{tabular}

\begin{tabular}{|c|c|c|c|c|c|}
\hline $1590-1594$ & $1595-1599$ & $1600-1604$ & $1605-1609$ & $1610-1614$ & total: 471 \\
\hline 69 & 29 & 42 & 71 & 50 & \\
\hline
\end{tabular}

Estos cuadros nos muestran cómo la actividad anti-islámica del Tribunal de Sicilia está directamente relacionada con la lucha política y militar en el Mediterráneo: fijémonos, por ejemplo, en el número de procesos en los años que siguen a Lepanto, en comparación con los años anteriores. Los procesos disminuirán considerablemente en la segunda mitad del siglo Xvıı, también en conformidad con la baja de tensión política en esta parte del mundo. (Debemos estas cifras globales a nuestro amigo Jaime Contreras, quien las expuso en su ponencia de Copenhagen; "Las causas de fe en la Inquisición española: 1540-1700. Análisis de una estadística").

su correligionario, otro, en fin, queda firme en su fe islámica, y hace todo lo posible para volver con los suyos. La señal de esta doble personalidad aparece en los dos nombres que suelen tener los acusados: así, Catalina de Barón se hace llamar Zara.

Los procesos de Inquisición nos han mostrado que hubo un problema morisco en Sicilia; existió con ciertas características particulares. Nunca tuvo la misma importancia que en España. Gracias a estas relaciones de causas, tenemos pruebas de la presencia morisca en Sicilia. No se puede cifrar esta población. Sin embargo, con las alusiones repetidas, podemos afirmar que fue uno de los componentes del cosmopolitismo de la isla. Por ejemplo, en 1551, se lee en el proceso de un tal Alí que "llevaba Moriscos Cristianos a Túnez a los tornar Moros". Varias veces se hace esta prohibición a los condenados: "No deben relacionarse con Moros o Moriscos". En la causa contra Catalina de Barón, ya citada, leemos: "En esta ciudad (Palermo), hay algunos Moriscos que son Cristianos baptiçados y viven como Moros, y se llaman nombres de tales, y así mismo mugeres moriscas..." Esta población vivía más bien en las ciudades marítimas que en los pueblos del interior. En las visitas que hacían los Inquisidores por los valles, no encontraron moriscos. 
En conclusión, el problema morisco en Sicilia es fundamentalmente el mismo que en España: es un conflicto de civilizaciones. Este conflicto, por ser escaso el número de moriscos, es en sí menos agudo (no hay peligro para los cristianos de sublevación morisca como en Aragón o en Valencia). Pero al mismo tiempo se tiene allí una conciencia más política del problema por la localización misma de Sicilia, situada en la zona conflictiva. La represión inquisitorial contra los moriscos no será más que uno de los aspectos del enfrentamiento con el Islam.

LOUIS CARDAILLAC

Université Paul Valéry, Montpellier. 